Thonne, C. B. \& Belton, F. C. (1957). J. gen. Microbiol. 17, 505-516

\title{
An Agar-Diffusion Method for Titrating Bacillus anthracis Immunizing Antigen and its Application to a Study of Antigen Production
}

\author{
By C. B. THORNE AND F. C. BELTON \\ Microbiological Research Establishment (Ministry of Supply) Porton, Wiltshire
}

SUMMARY: An agar-diffusion method is described for the titration of Bacillus anthracis immunizing antigen and antibody. It is a sensitive and simple method that can be used for determining antigen concentrations in culture filtrates and for titrating antisera from animals and humans which have been immunized with the antigen. Marked improvements in yields of antigen in a defined medium and a hydrolysed casein + amino acids (Casamino) medium have been achieved with the aid of this assay method.

Although much information has been gained from studies on the protective antigen present in culture filtrates of Bacillus anthracis when the organism is grown under certain conditions (Gladstone, 1946, 1948; Wright, Hedberg \& Slein, 1954; Puziss \& Wright, 1954; Belton \& Strange, 1954; Strange \& Belton, 1954), research on this antigen has been hampered by the lack of convenient assay methods for the antigen and its antibody. Recently Belton \& Henderson (1956) developed a skin test in rabbits for assaying the immunizing antigen and antibody, based on the capacity of antiserum to neutralize anthrax toxin. This method proved to be valuable for assaying antigen preparations and particularly useful in titrating immune sera. The present paper describes another assay procedure, an agar-diffusion method based on the technique of Ouchterlony (1953), which is much simpler and more sensitive than the rabbit skin test. We have used the new assay method with good results in a study of some factors which affect production of antigen. Studies by Wright et al. (1954), Puziss \& Wright (1954) and Belton \& Strange (1954) resulted in methods for producing immunizing antigen in protein-free media. The present investigation was undertaken to improve yields of antigen in order to facilitate research on the more fundamental aspects of its biochemistry.

\section{METHODS}

Organisms. Most of the work on antigen production was done with the avirulent Weybridge strain isolated by Sterne (1937) and used by the Ministry of Agriculture, Fisheries and Food as a living spore vaccine. A few experiments were done with the following strains: Vollum; N.P.A., a virulent non-proteolytic mutant from Vollum; M-36; BI, an avirulent strain. Spore suspensions were prepared as described by Belton \& Strange (1954).

Media and methods for antigen production. The defined medium was the 599 medium described by Puziss \& Wright (1954) for antigen production. It 
contained 14 amino acids, guanine, thiamine, $\mathrm{CaCl}_{2}, \mathrm{MgSO}_{4}, \mathrm{MnSO}_{4}, \mathrm{FeSO}_{4}$, $\mathrm{K}_{2} \mathrm{HPO}_{4}, \mathrm{KH}_{2} \mathrm{PO}_{4}, \mathrm{NaHCO}_{3}$, and glucose. The 'Casamino acids' medium, which was developed by Belton \& Strange (1954) for antigen production, contained Difco Casamino Acids, glycine, tryptophan, cystine, glutamine, adenine, uracil, guanine, thiamine, glucose, $\mathrm{NaHCO}_{3}$, salts as in 599 medium, and charcoal. Media were prepared with distilled water which had been passed through an Amberlite resin (Belton \& Strange, 1954) and were autoclaved at pH 6.9 for $15-20 \mathrm{~min}$. at $15 \mathrm{lb}$./sq.in. Glutamine, glucose, $\mathrm{NaHCO}_{3}$, and $\mathrm{FeSO}_{4}$, when used at the original concentration of $0.0005 \mathrm{M}$, were sterilized by filtration. When the concentration of $\mathrm{FeSO}_{4}$ was $0 \cdot 000025 \mathrm{M}$ it was autoclaved in the medium.

Cultures were grown at $37^{\circ}$ either in 31 . Thompson bottles containing $500 \mathrm{ml}$. medium or in $250 \mathrm{ml}$. Erlenmeyer flasks containing $100 \mathrm{ml}$. The inoculum was either $10^{6}$ spores or $0.1 \mathrm{ml}$. of a $24 \mathrm{hr}$. shaken culture grown in the defined medium without $\mathrm{NaHCO}_{3}$. Thompson bottles were incubated statically and flasks were incubated either statically or on a reciprocating shaker with a stroke distance of $2.5 \mathrm{~cm}$. and a speed of $110 \mathrm{cycles} / \mathrm{min}$. The time of incubation varied and is given for individual experiments.

Preparation of samples for assay. Cultures were filtered through sintered glass and usually $10 \mathrm{ml}$. samples of filtrates were lyophilized with $0.5 \mathrm{ml}$. of normal horse serum. This was a convenient procedure since serum stabilized the antigen to lyophilization and such samples could be stored for later reference. At other times samples were assayed directly after adding $5 \%$ $(\mathrm{v} / \mathrm{v})$ horse serum. In experiments testing the effect of gelatin on the stability of antigen to lyophilization $10 \%(\mathrm{v} / \mathrm{v})$ of a $2 \%(\mathrm{w} / \mathrm{v})$ solution in $0.02 \mathrm{M}-$ phosphate ( $\mathrm{pH} \mathrm{8.0)}$ was added. For testing the effect of gelatin on the assay method either $5 \%(\mathrm{v} / \mathrm{v})$ of the gelatin solution was added directly to the sample before diluting it in saline or dilutions were made in $0.5 \%(\mathrm{w} / \mathrm{v})$ gelatin in $0.02 \mathrm{M}$-phosphate ( $\mathrm{pH} \mathrm{8.0)}$. Potencies were estimated by the agar diffusion method and improvements in yields were confirmed by the toxin neutralization test (Belton \& Henderson, 1956) and/or immunization tests in rabbits.

Immunization tests. Rabbits of heterogeneous strains weighing about $5 \mathrm{lb}$. were used. Five doses of $0.5 \mathrm{ml}$. each of appropriately diluted samples of antigen were given subcutaneously at 2-day intervals and the animals were challenged with an intradermal injection of 500 spores (250 lethal doses) of Bacillus anthracis strain M-36, 7 days after the last dose of antigen. Results are reported as survival ratios, i.e. the number of animals surviving divided by the number challenged.

Medium for agar diffusion plates. $1 \%$ agar dissolved in $\mathbf{0 . 0 7 5} \mathrm{M}$-phosphate buffer ( $\mathrm{pH} \mathrm{7.3)}$ containing $0.9 \% \mathrm{NaCl}$ and $0.01 \%$ thiomersalate.

Antisera. Antiserum H-533 prepared in a horse by injecting Weybridge spores was used routinely. Antiserum $\mathbf{H}-25$ prepared in a horse by injecting alum precipitated antigen (Belton \& Strange, 1954) was used in some of the tests. In addition two samples of hyperimmune spore antisera produced in horses for commercial use were supplied by $\mathrm{Dr} \mathbf{H}$. N. Spears (Ministry of 
Agriculture, Fisheries and Food Laboratories, Weybridge). One of these had been lyophilized and stored for two years.

Standard antigen. A large batch of culture filtrate from the Weybridge strain grown in the improved Casamino acids medium was lyophilized in $10 \mathrm{ml}$. portions with $0.5 \mathrm{ml}$. of normal horse serum. This preparation, S-172, which had a titre of $1 / 19 \cdot 2$ in the agar diffusion assay with the standard antiserum H-533, was used as a standard antigen for antibody titrations and for comparing line patterns of other antigen preparations.

Titration of antigen. Twelve ml. of the agar medium were used in each Petri dish $(9 \mathrm{~cm}$. diam.) and circular reservoirs were made in the solidified agar with cork borers. Plates prepared in this manner were stored at $2^{\circ}$ and used as required. Several sizes and arrangements of reservoirs were tested and best results were obtained with a plan designed by Dr T. W. Burrows of this department (Pl. 1, figs. 1, 2). A pattern with holes to accommodate cork borers of the appropriate sizes was made of Perspex to fit over a Petri dish. The holes in the two outer rows are $7 \mathrm{~mm}$. in diameter and are spaced $5 \mathrm{~mm}$. apart and $6 \mathrm{~mm}$. from the inner row of holes which are $5 \mathrm{~mm}$. in diameter and $7 \mathrm{~mm}$. apart.

The inner reservoirs were filled with undiluted antiserum and the pletes were held at $2^{\circ}$ for 18-24 hr. The outer reservoirs were then filled with appropriate dilutions of antigen samples in saline (or in $0.5 \%, \mathrm{w} / \mathrm{v}$ ) gelatin in $0.02 \mathrm{M}$-phosphate ( $\mathrm{pH} 8.0$, when horse serum or gelatin had not been added to the sample), after which the plates were kept at room temperature. Plates were usually observed after 20-24 hr. for lines of precipitation by holding over a light against a black background, but final readings were not made until the second day. The highest dilution which produced a visible line was taken as the end point.

As a first approximation of potency usually five successive twofold dilutions of each of two samples were put on a single plate. After the potency had been determined in this manner it was possible to do a closer titration by diluting samples over a twofold range in five steps differing by dilution factors of 10/12, $10 / 14,10 / 16,10 / 18$ and 10/20. With these close dilution factors the end point was still clearly visible and reproducible.

Titration of antibody. Antibody was titrated by determining the capacity of test antiserum to combine with standard antigen and to prevent its forming a line of precipitation with a standard antiserum in agar diffusion plates. The concentration of antigen in a $1 / 8$ final dilution of the standard preparation, S-172, was found convenient and suitable for antibody assays. Samples, usually $\mathbf{0 . 2} \mathrm{ml}$., of the standard antigen diluted $1 / 4$ in saline, were mixed with equal volumes of serial twofold dilutions of the test antiserum. The resulting solutions were added directly to antigen reservoirs in agar plates prepared as described for antigen titrations with standard antiserum H-533 in the centre reservoirs. The end-point was taken as the highest final dilution of test antiserum that prevented formation of a visible line. 


\section{RESULTS}

\section{Antigen titrations}

Pl. 1, fig. 1, shows a typical plate with two samples assayed against antiserum H-533. In the upper part of the plate the five reservoirs contained a lyophilized filtrate from the Weybridge strain at dilutions of $1,1 / 2,1 / 4,1 / 8$ and $1 / 16$ respectively from left to right. The line of precipitation did not extend beyond the fourth reservoir and therefore the titre was $1 / 8<1 / 16$. The reservoirs in the lower half of the plate contained a lyophilized filtrate from the Vollum strain reconstituted to $2,1,1 / 2,1 / 4$ and $1 / 8$ times the original concentration. The titre of this sample was $1 / 2<1 / 4$.

Since the titre of a sample depends not only on the concentration of antigen but also on the strength of the antiserum used, the test antiserum must be identified when potencies are expressed. For example, with a sample of partially purified antigen the end-point was reached at a concentration of about $4 \mu \mathrm{g} . / \mathrm{ml}$. in titrations against antiserum $\mathbf{H}-533$ and about $8 \mu \mathrm{g} . / \mathrm{ml}$. in titrations against antiserum $\mathbf{H}-25$.

Reproducibility of results. Table 1 shows results obtained when each of four lyophilized culture filtrates was assayed four times. The data demonstrate that results were highly reproducible over a period of time.

\section{Table 1. Reproducibility of antigen titrations by the agar diffusion method}

\begin{tabular}{|c|c|c|c|c|}
\hline \multirow{2}{*}{$\begin{array}{c}\text { Sample } \\
\text { no. }\end{array}$} & \multicolumn{4}{|c|}{ Titre obtained against antiserum $\mathbf{H - 5 3 3}$ on given date } \\
\hline & 5 Nov. & 8 Nov. & 30 Nov. & 1 Mar. \\
\hline 1 & $1 / 2<1 / 4$ & $1 / 2<1 / 2 \cdot 4$ & $1 / 2<1 / 2 \cdot 4$ & $1 / 2<1 / 2 \cdot 4$ \\
\hline 2 & $1 / 4<1 / 8$ & $1 / 5 \cdot 6<1 / 6.4$ & $1 / 5 \cdot 6<1 / 6.4$ & $1 / 4.8<1 / 5.6$ \\
\hline 3 & $1 / 8<1 / 16$ & $1 / 9 \cdot 6<1 / 11 \cdot 6$ & $1 / 9 \cdot 6<1 \cdot 11 / 2$ & $1 / 9 \cdot 6<1 / 11 \cdot 2$ \\
\hline 4 & $1 / 8<1 / 16$ & $1 / 14 \cdot 4<1 / 16$ & $1 / 12.8<1 / 14.4$ & $1 / 12 \cdot 8<1 / 14 \cdot 4$ \\
\hline
\end{tabular}

Effect of normal serum and gelatin. The addition of normal horse serum to samples (see under Preparation of samples for assay) served two purposes; it stabilized the antigen to lyophilization and increased the sensitivity of the agar diffusion method about twofold. This effect of serum on the assay was observed repeatedly with a purified antigen preparation and culture filtrates. The effect was not a specific one of serum, however, since the same results with the assay method and in the protection of antigen to lyophilization were obtained when gelatin was substituted for serum.

Results with other antisera. The two hyperimmune sera obtained from the Ministry of Agriculture, Fisheries and Food (Weybridge Laboratories) were used to assay several samples of antigen which were also titrated against antiserum H-533. Results obtained with the three antisera were identical.

Correlation of results with animal tests. Before one could rely on the agar diffusion assay as a method for estimating actual immunizing potencies, it was necessary to test several samples both by the new method and by animal protection tests. Since it had been shown earlier that results of the rabbit skin 
test for anthrax toxin neutralization (Belton \& Henderson, 1956) closely paralleled results of animal protection tests, this method of testing potencies was included. Results of testing five samples by the three methods are shown in Table 2. Potencies as determined by the skin test and the agar diffusion method agreed closely and the relative potencies were confirmed by the immunization tests. These results, as well as others from later experiments, indicate that the agar diffusion assay is reliable for titrating antigen.

\section{Table 2. Comparison of three methods for estimating potencies of antigen samples}

\begin{tabular}{|c|c|c|c|c|c|c|c|c|}
\hline \multirow{2}{*}{$\begin{array}{l}\text { Culture } \\
\text { filtrate } \\
\text { no. }\end{array}$} & \multirow[b]{2}{*}{ Medium* } & \multirow{2}{*}{$\begin{array}{l}\text { Highest } \\
\text { dilution } \\
\text { active in } \\
\text { rabbit skin } \\
\text { test }\end{array}$} & \multirow{2}{*}{$\begin{array}{c}\text { Titre against } \\
\text { antiserum H-533 } \\
\text { in agar dif- } \\
\text { fusion plates }\end{array}$} & \multicolumn{5}{|c|}{$\begin{array}{l}\text { Immunizing activity for } \\
\text { rabbits : survival ratios } \dagger \\
\text { at given dilutions }\end{array}$} \\
\hline & & & & $\begin{array}{l}\text { Un- } \\
\text { diluted }\end{array}$ & $1 / 5$ & $1 / 15$ & $1 / 25$ & $1 / 50$ \\
\hline 1 & $\begin{array}{l}\text { Casamino acids medium } \\
\text { of Belton \& Strange } \\
\text { (1954) without charcoal }\end{array}$ & $1<1 / 2$ & $1 / 1 \cdot 4<1 / 1 \cdot 6$ & $4 / 4$ & $3 / 4$ & $1 / 4$ & . & . \\
\hline 2 & $\begin{array}{l}\text { Same as } 1 \text { with } 0.1 \% \\
(w / v) \text { charcoal }\end{array}$ & $1 / 2<1 / 4$ & $1 / 3 \cdot 2<1 / 3 \cdot 6$ & . & $4 / 4$ & $2 / 4$ & $1 / 4$ & . \\
\hline 3 & $\begin{array}{l}\text { Same as } 1 \text { with } 0 \cdot 1 \% \\
(w / v) \text { charcoal and } 5 \% \\
(v / v) \text { sheep serum }\end{array}$ & $1 / 8<1 / 16$ & $1 / 6 \cdot 4<1 / 7 \cdot 2$ & . & $4 / 4$ & . & $4 / 4$ & $3 / 4$ \\
\hline 4 & $\begin{array}{l}599 \text { medium of Puziss } \\
\& \text { Wright }(1954) \text { with } \\
0.05 \%(w / v) \text { charcoal }\end{array}$ & $1 / 2<1 / 4$ & $1 / 1 \cdot 6<1 / 1 \cdot 8$ & . & $2 / 4$ & $2 / 4$ & $1 / 4$ & - \\
\hline 5 & $\begin{array}{l}\text { Same as } 4 \text { with } 5 \% \\
(v / v) \text { horse serum }\end{array}$ & $1 / 8<1 / 16$ & $1 / 11 \cdot 2<1 / 12 \cdot 8$ & . & $4 / 4$ & . & $4 \cdot 4$ & $3 / 4$ \\
\hline
\end{tabular}

* The Weybridge strain was grown in Thompson bottles. Those with Casamino acids medium were incubated $22 \mathrm{hr}$. and those with defined medium were incubated $40 \mathrm{hr}$.

$\dagger$ Survival ratios of rabbits immunized with given dilutions of antigen and challenged by intradermal injection of spores.

Multiple lines of precipitation. Samples taken from static cultures at or before the time of maximum antigen yield formed only one line of precipitation when tested at filtrate concentration or after diluting. More concentrated samples of such filtrates, as well as diluted samples of filtrates prepared under various other conditions, often formed more than one line. This was true with filtrates from older cultures and particularly so with samples from shaken cultures in which antigen formation and destruction both occurred more rapidly than in static cultures.

Pl. 1, fig. 2, shows lines formed by four representative filtrates, described in Table 3, when tested at two concentrations. The upper row of reservoirs contained the samples at filtrate concentration and the lower row contained the same samples concentrated fourfold. The main line formed by the standard antigen preparation S-172 merged with the main line formed by the other filtrates, with the exception of sample 300, the line of which crossed the line of S-172. Data in Table 3 show that all samples except 300 had immunizing activities correlating with titres as determined by the agar diffusion method. 


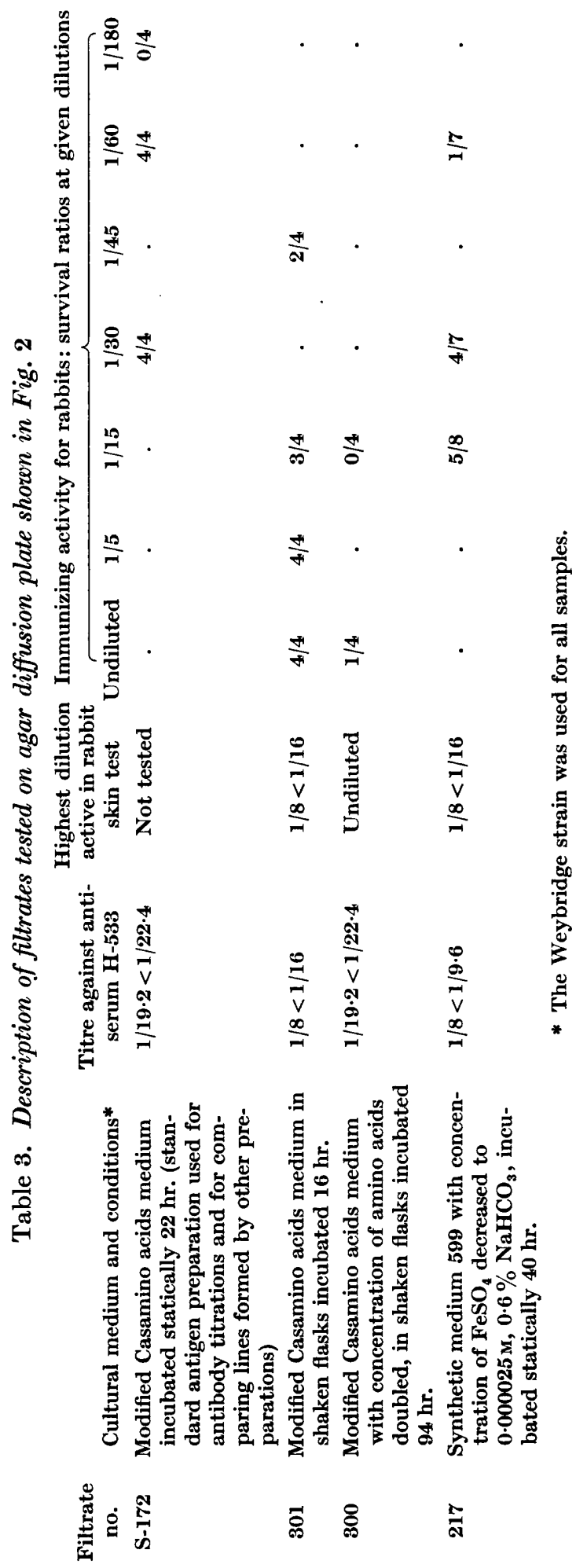


This correlation of line patterns with immunizing activity was observed repeatedly. Of a number of samples tested those that formed a line which merged with the main line of S-172 had immunizing activity. These observations demonstrate that the antigen which produced the line given by sample 300 had insignificant protective activity and they provide evidence that the antigen responsible for the main line formed by the standard preparation S-172 represented a protective antigen. As many as five lines have been observed with highly concentrated filtrates or filtrate from old cultures. The nature of the antigens which form the various lines has not yet been ascertained. Possibilities to be considered are that some of them represent other protective antigens, precursors or degraded products of a single protective antigen, or antigens not related to the protective antigen.

\section{Antibody titrations}

Each of 250 human sera was titrated by the agar diffusion method and by the rabbit skin test for toxin neutralization; the titres obtained by the two methods agreed closely. Table 4 presents results obtained when ten representative antisera were titrated three times by the agar diffusion method. The data show that results were reproducible and that they agreed closely with results from the skin test. This new method has also been used to titrate antisera from rabbits, guinea pigs and horses, including some with titres as high as $1 / 1600$.

Table 4. Reproducibility of antibody titrations

\begin{tabular}{|c|c|c|c|c|}
\hline \multirow[b]{2}{*}{$\begin{array}{c}\text { Antiserum } \\
\text { no. }\end{array}$} & \multirow{2}{*}{$\begin{array}{c}\text { Titre by toxin } \\
\text { neutralization } \\
\text { test }\end{array}$} & \multicolumn{3}{|c|}{ Titre by agar diffusion method } \\
\hline & & $\begin{array}{c}\text { First } \\
\text { test }\end{array}$ & $\begin{array}{l}\text { Second } \\
\text { test }\end{array}$ & $\begin{array}{l}\text { Third } \\
\text { test }\end{array}$ \\
\hline 1 & $1 / 8$ & $1 / 4$ & $1 / 4$ & $1 / 4$ \\
\hline 2 & $1 / 8$ & $1 / 8$ & $1 / 8$ & $1 / 8$ \\
\hline 3 & $1 / 4$ & $1 / 4$ & $1 / 4$ & $1 / 2$ \\
\hline 4 & $1 / 8$ & $1 / 8$ & $1 / 4$ & $1 / 4$ \\
\hline 5 & $1 / 16$ & $1 / 16$ & $1 / 16$ & $1 / 16$ \\
\hline 6 & $1 / 2$ & $1 / 4$ & $1 / 2$ & $1 / 2$ \\
\hline 7 & Nil & Nil & Nil & Nil \\
\hline 8 & $1 / 4$ & $1 / 4$ & $1 / 4$ & $1 / 4$ \\
\hline 9 & $1 / 16$ & $1 / 16$ & $1 / 32$ & $1 / 16$ \\
\hline 10 & $1 / 16$ & $1 / 16$ & $1 / 16$ & $1 / 16$ \\
\hline Normal serum & Nil & Nil & Nil & Nil \\
\hline
\end{tabular}

\section{Studies on antigen production}

Definied medium for growth. When the defined medium was tested with the Weybridge strain in flasks or Thompson bottles, filtrates had antigen titres of 1 or $\frac{1}{2}$ against antiserum $\mathbf{H - 5 3 3}$. The yield of antigen was increased at least eightfold by making the modifications in the medium described below.

A decrease in the concentration of $\mathrm{FeSO}_{4}$ resulted in a higher yield of antigen; the yield was doubled when the concentration was reduced from 0.0005 to $0.000025 \mathrm{M}$. In experiments with a vegetative inoculum it was shown 
that $\mathrm{FeSO}_{4}$ need not be omitted from the medium, although traces were introduced with the inoculum since it was grown in the defined medium containing 0.000025 $\mathrm{M}-\mathrm{FeSO}_{4}$. However, when a spore inoculum was used and $\mathrm{FeSO}_{4}$ not added, the organism grew very slowly, as had been shown by Puziss \& Wright (1954).

Belton \& Strange (1954) obtained higher yields of antigen by adding charcoal to the Casamino acids medium. We have found that charcoal has a similar effect in the defined medium. The reason for this effect of charcoal is not clear. It was also shown previously that to be effective the charcoal had to be present in the medium during growth; this was confirmed in the defined medium. When charcoal was autoclaved with the medium and then removed by filtration or when it was added aseptically to the culture at $24 \mathrm{hr}$. there was no effect on antigen yields.

The effects of various concentrations of $\mathrm{NaHCO}_{3}$ on antigen yields are shown in Table 5. Without $\mathrm{NaHCO}_{3}$ no detectable antigen was produced. This is in agreement with results obtained by Gladstone (1946) and Puziss \& Wright (1954). When the concentration of $\mathrm{NaHCO}_{3}$ was increased to 0.5 or $0.75 \%$ $(\mathrm{w} / \mathrm{v})$ the antigen yields increased about fourfold, but a concentration of $1.0 \%(w / v)$ was greater than the optimum concentration. From these results and those of similar experiments a concentration of $0.6 \%(\mathrm{w} / \mathrm{v})$ was selected for routine use. With the increased concentration of $\mathrm{NaHCO}_{3}$ in the defined medium it was necessary to use a vegetative inoculum. Poor growth and low antigen yields resulted when spore inocula were used.

Table 5. Effect of $\mathrm{NaHCO}_{3}$ on antigen yields in the medium*

\begin{tabular}{|c|c|c|c|c|}
\hline \multirow{2}{*}{$\begin{array}{l}\mathrm{NaHCO}_{0} \\
\%(w / v)\end{array}$} & \multicolumn{2}{|c|}{$\mathrm{pH}$ value of filtrate } & \multicolumn{2}{|c|}{$\begin{array}{l}\text { Titre of filtrate: } \\
\text { against antiserum } \mathbf{H - 5 3 3}\end{array}$} \\
\hline & $22 \mathrm{hr}$. & $40 \mathrm{hr}$. & $22 \mathrm{hr}$. & $40 \mathrm{hr}$. \\
\hline 0 & . & $7 \cdot 0$ & $<1$ & $<1$ \\
\hline 0.25 & . & $8 \cdot 3$ & $<1$ & $1 / 2<1 / 4$ \\
\hline 0.50 & $8 \cdot 6$ & $8 \cdot 5$ & $1 / 2<1 / 4$ & $1 / 8<1 / 16$ \\
\hline 0.75 & $8 \cdot 8$ & $8 \cdot 8$ & $1 / 2<1 / 4$ & $1 / 8<1 / 16$ \\
\hline $1 \cdot 0$ & $9 \cdot 0$ & $9 \cdot 0$ & $1<1 / 2$ & $1 / 4<1 / 8$ \\
\hline
\end{tabular}

* 599 medium with $0.000025 \mathrm{M}-\mathrm{FeSO}_{4} ; 100 \mathrm{ml}$. in $250 \mathrm{ml}$. Erlenmeyer flasks incubated statically; vegetative inoculum, Weybridge strain; $\mathrm{pH} 6.9$ before addition of $\mathrm{NaHCO}_{3}$.

A few experiments were done on the effect of replacing $\mathrm{NaHCO}_{3}$ with Tris (tris-(hydroxymethyl)-aminomethane) buffer. Without added $\mathrm{NaHCO}_{3}$ antigen was produced when $0.05 \mathrm{M}$-Tris was used at a sufficiently high initial $\mathrm{pH}$ value, i.e. $8 \cdot 7-9 \cdot 5$, although the yields with Tris were lower than those with $\mathrm{NaHCO}_{3}$. These results suggested that bicarbonate may not be essential for antigen synthesis but that its function in the medium may be to provide and maintain a favourable $\mathrm{pH}$ value. However, with Tris buffer at a high $\mathrm{pH}$ value enough $\mathrm{CO}_{2}$ might have been retained from that produced by the organism to supply sufficient bicarbonate for antigen synthesis.

Table 6 shows the yields of antigen obtained with various modifications of 
Anthrax antigen assay

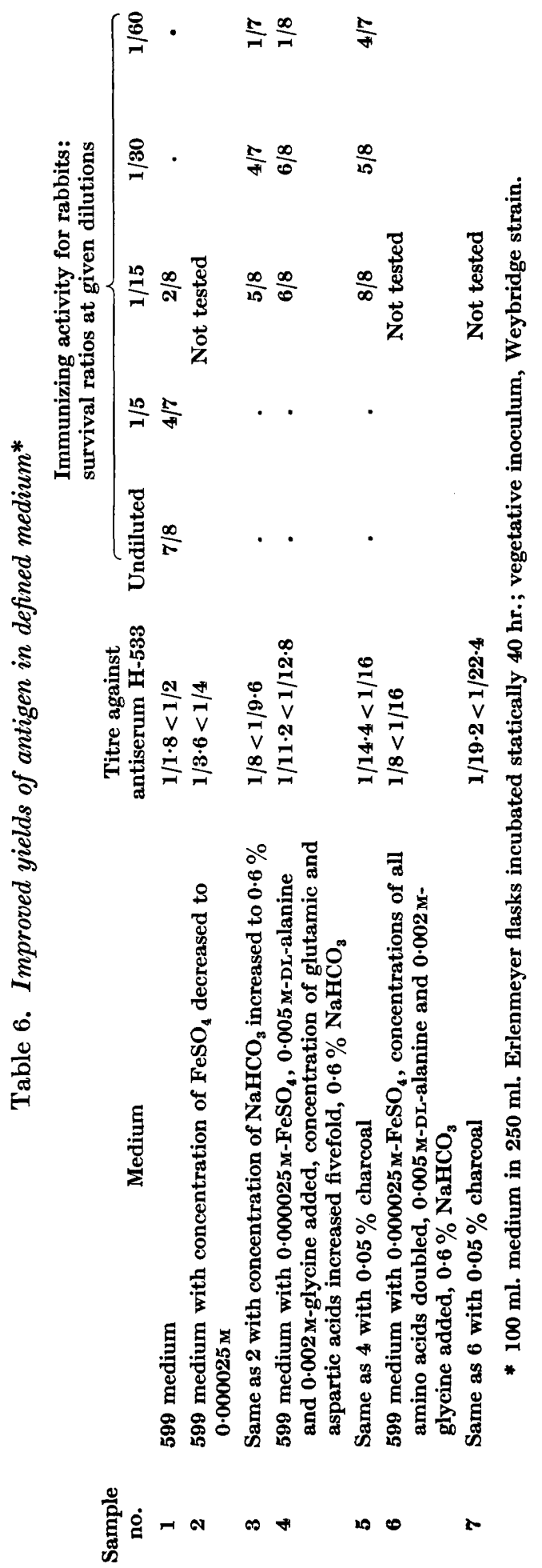


the defined medium and gives the results of some protective tests in rabbits. With the increased concentration of $\mathrm{NaHCO}_{3}$ and the decreased concentration of $\mathrm{FeSO}_{4}$ yields were improved further when the medium was enriched with alanine and glycine and when the concentrations of other amino acids were increased. Maximum yields occurred at $32-40 \mathrm{hr}$. The results of rabbit protection tests confirmed the improved yields in those samples which were tested.

- Casamino acids medium. Yields of antigen from static cultures grown in Casamino acids medium were increased several-fold when $\mathrm{FeSO}_{4}$ was not added and the concentration of $\mathrm{NaHCO}_{3}$ increased to 0.5 or $0.6 \%(\mathrm{w} / \mathrm{v})$. Additional studies revealed that the medium could be simplified by omitting glutamine and guanine, and yields of antigen were improved further by replacing the potassium phosphate by $424 \mathrm{mg}$. $\mathrm{KCl} / \mathrm{l}$. (It should be pointed out that Difco casamino acids contain small amounts of iron and phosphate.) Table 7 shows yields that were obtained with the original and modified media. The increase of yields of antigen as determined by the agar diffusion method of assay was confirmed by animal tests.

When other strains of Bacillus anthracis, namely BI, Vollum, N.P.A. and M-36, were tested, yields of antigen were 4-8 times higher in the modified casamino acids medium than in the original medium.

Shaken flask cultures. When the modified Casamino acids medium (as given above except with the original amount of phosphate buffer) was tested in shaken flasks, interesting results were obtained. An antigen titre of $1 / 8$ against antiserum $\mathrm{H}-533$ was produced in 16-18 hr. and it decreased very rapidly during the next $8 \mathrm{hr}$. With the decrease in antigen titre, as determined by the agar diffusion method as well as by animal tests, interesting changes in the pattern of lines occurred. When the titre was at its peak usually only one line was observed and as the titre decreased multiple lines appeared. The results suggested that the antigen was perhaps being degraded into smaller fragments.

When a richer medium prepared by doubling the concentration of casamino acids was tested in shaken flasks filtrates of 14-20 hr. cultures formed a line which merged with that of the standard preparation, S-172. After $20 \mathrm{hr}$. this antigen disappeared rapidly and antigen forming a different line appeared as shown by sample 300 in Fig. 2. Although the titres of this antigen were as high as $1 / 16$ to $1 / 32$, such filtrates had insignificant activity in toxin neutralization and immunization tests.

\section{Conclusion}

The agar diffusion method is a simple and inexpensive assay procedure for the protective antigen of Bacillus anthracis. Being sensitive enough to detect relatively small changes in antigen concentration, it should be useful in studies on fundamental aspects of the organism's physiology relating to antigen synthesis. The method, as well as the increased antigen yields resulting from the present study, should be valuable in research on isolation and identification of the active principle. The method for titrating antibody is a simple one that should be useful in anthrax immunity studies. 


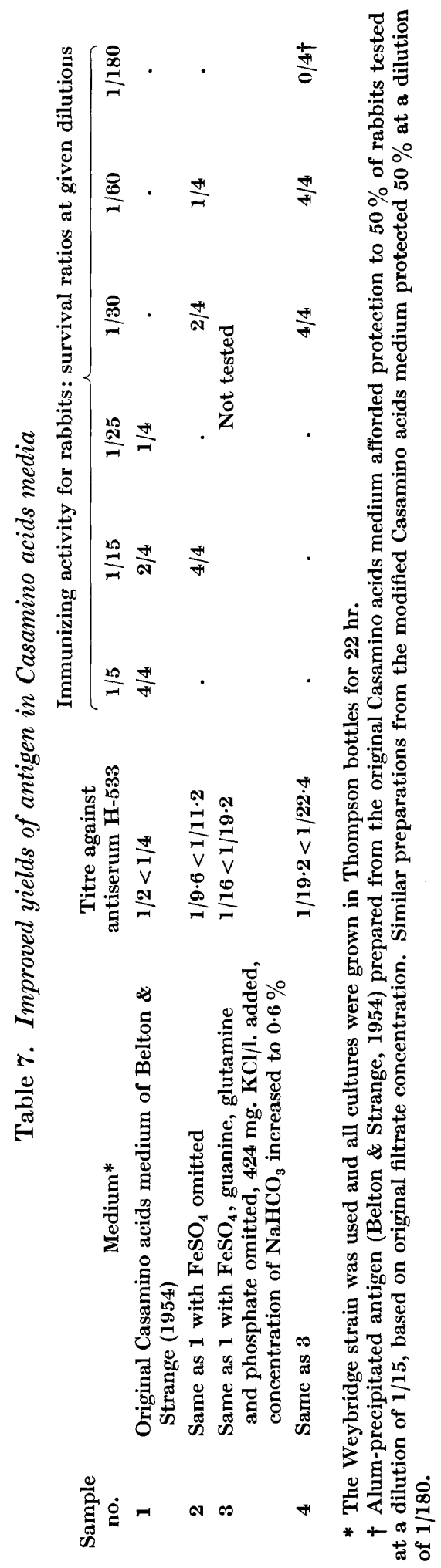


It is a pleasure to acknowledge the helpful suggestions of Dr D. W. Henderson. We are also grateful to Dr H. N. Spears of the Ministry of Agriculture, Fisheries and Food (Weybridge Laboratories) for two samples of hyperimmune horse sera. This work was done during a year's working visit by one of us (C.B.T.) from Fort Detrick, Frederick, Maryland, U.S.A.

\section{REFERENCES}

Belton, F. C. \& Henderson, D. W. (1956). A method for assaying anthrax immunising antigen and antibody. Brit. J. exp. Path. 37, 156.

Belton, F. C. \& Strange, R. E. (1954). Studies on a protective antigen produced in vitro from Bacillus anthracis: medium and methods of production. Brit. J. exp. Path. 35, 144.

Gladstone, G. P. (1946). Immunity to anthrax: protective antigen present in cellfree culture filtrates. Brit. J. exp. Path. 27, 394.

Gladstone, G. P. (1948). Immunity to anthrax: production of the cell-free protective antigen in cellophane sacs. Brit. J. exp. Path. 29, 379.

Ouchterlony, O. (1953). Antigen-antibody reactions in gels. IV. Types of reactions in co-ordinated systems of diffusion. Acta path. microbiol. Scand. 32, 231.

Puziss, M. \& Wright, G. G. (1954). Studies on immunity in anthrax. IV. Factors influencing elaboration of the protective antigen of Bacillus anthracis in chemically defined media. $J$. Bact. 68, 474 .

STERNe, M. (1937). Variation in Bacillus anthracis. Onderstepoort J. vet. Sci. 8, 271.

Strange, R. E. \& Belton, F. C. (1954). Studies on a protective antigen produced in vitro from Bacillus anthracis: purification and chemistry of the antigen. Brit. J. exp. Path. 35, 153.

Wright, G. G., Hedberg, M. A. \& Slein, J. B. (1954). Studies on immunity in anthrax. III. Elaboration of protective antigen in a chemically-defined nonprotein medium. J. Immunol. 72, 263.

\section{EXPLANATION OF PLATE}

Fig. 1. Agar diffusion plate demonstrating titrations of antigen in two culture filtrates.

Fig. 2. Agar diffusion plate showing line patterns formed by four different culture filtrates at two concentrations. 
Journal of General Microbiology, Vol. 17, No. 2

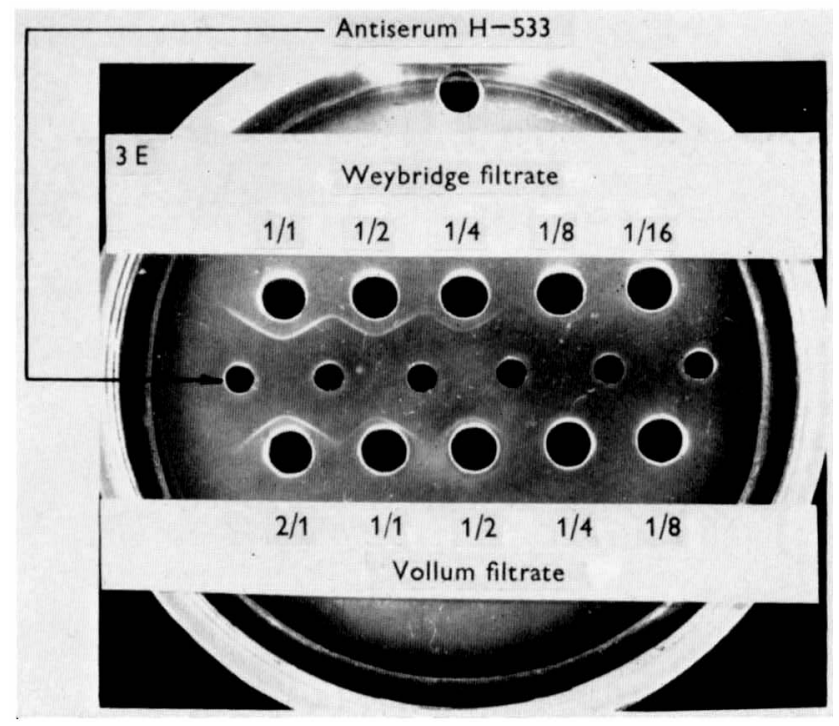

Fig. 1

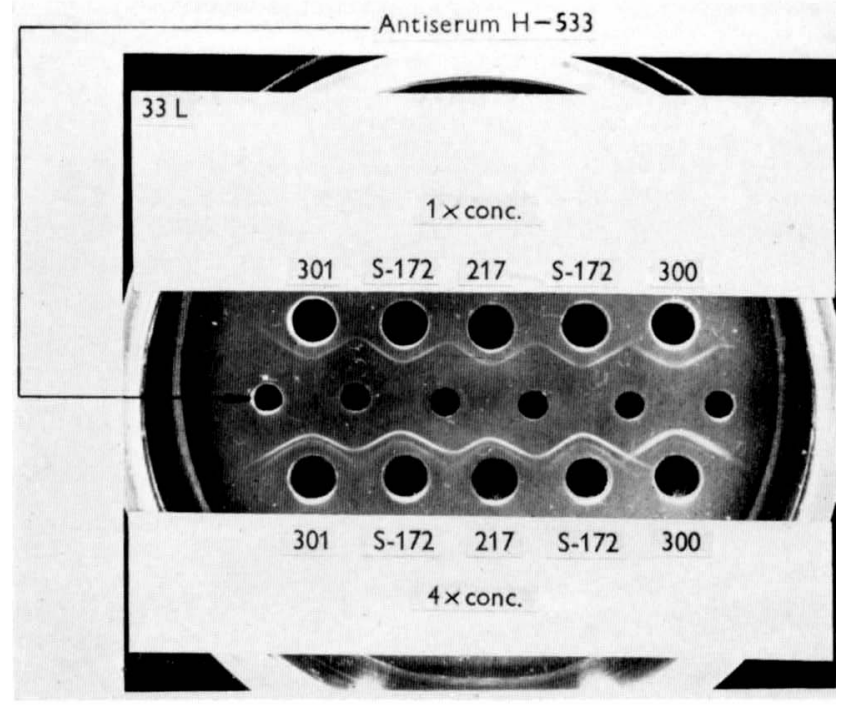

Fig 2

C. B. 'Ihorne \& F. C. Belton-Anthrax antigen assay. Plate 1

(Facing p. 516) 